\title{
Correction to: Al-Empowered Process Mining for Complex Application Scenarios: Survey and Discussion
}

\author{
Francesco Folino ${ }^{1}$ (D) $\cdot$ Luigi Pontieri ${ }^{1}$ (C)
}

Published online: 24 June 2021

(c) Springer-Verlag GmbH Germany, part of Springer Nature 2021

\section{Correction to: \\ Journal on Data Semantics \\ https://doi.org/10.1007/s13740-021-00121-2}

In the Original Publication, 'Acknowledgements' section given below was unfortunately missed out. The original publication has been updated of the same.

Acknowledgements This work was partially supported by the European Commission funded project "Humane AI: Toward AI Systems That Augment and Empower Humans by Understanding Us, our Society and the World Around Us" (Grant \# 820437). The support is gratefully acknowledged.

Publisher's Note Springer Nature remains neutral with regard to jurisdictional claims in published maps and institutional affiliations.

The original article can be found online at https://doi.org/10.1007/ s13740-021-00121-2.

\footnotetext{
Luigi Pontieri

luigi.pontieri@icar.cnr.it

Francesco Folino

francesco.folino@icar.cnr.it

1 Institute ICAR-CNR, Via P. Bucci 8/9C, 87036 Rende, CS,

Italy
} 